\begin{tabular}{|l|l|l||}
\hline \multicolumn{2}{|c|}{ PublisherInfo } \\
\hline \hline PublisherName & $:$ & BioMed Central \\
\hline \hline PublisherLocation & $:$ & London \\
\hline \hline PublisherImprintName & $:$ & BioMed Central \\
\hline \hline
\end{tabular}

\title{
Brucellagenome fever
}

\begin{tabular}{|l|l|l||}
\hline \multicolumn{2}{|c|}{ ArticleInfo } \\
\hline \hline ArticleID & $:$ & 4331 \\
\hline \hline ArticleDOI & $:$ & $10.1186 /$ gb-2002-3-4-reports0020 \\
\hline \hline ArticleCitationID & $:$ & reports0020 \\
\hline \hline ArticleSequenceNumber & $:$ & 21 \\
\hline \hline ArticleCategory & $:$ & Paper report \\
\hline \hline ArticleFirstPage & $:$ & 1 \\
\hline \hline ArticleLastPage & $:$ & 4 \\
\hline \hline & & RegistrationDate : 2002-1-21 \\
ArticleHistory & $:$ & Received \\
& & OnlineDate 2002-1-21 \\
\hline \hline ArticleCopyright & $:$ & BioMed Central Ltd2002-3-15 \\
\hline \hline ArticleGrants & $:$ & \\
\hline \hline
\end{tabular}




\begin{tabular}{|l|l|l||}
\hline ArticleContext & $:$ & 130593344 \\
\hline
\end{tabular}

\section{Wim D'Haeze}

\section{Abstract}

The entire Brucella melitensis genome sequence could pave the way to a vaccine against brucellosis in humans

\section{Significance and context}

In 1887 the British army surgeon Sir David Bruce discovered the organism that caused Malta fever in humans. This organism is now better known as the facultative intracellular bacterial pathogen Brucella melitensis. Infection with $B$. melitensis causes abortion in goats and sheep and Malta fever in humans; it is still reported from Mediterranean regions and parts of Asia, Africa and Latin America. The symptoms are comparable with those at the start of influenza. Humans can get infected when they come into contact with unpasteurized milk or milk products, or infected animals. During the early stages of infection, $B$. melitensis enters macrophages, where it adapts to the acidic environment in vacuoles; it multiplies in the vacuolar compartment and prevents fusion of phagosomes with lysosomes. Brucellosis in humans spreads easily and no vaccines are yet available. This, together with the fact that Brucella pathogenesis is poorly understood, provided the impetus for an in-depth study of this bacterial pathogen, the entire genome sequence of which is now available for further research.

\section{Key results}

The complete $B$. melitensisgenome contains 3,294,931 base pairs (bp) and consists of two chromosomes - chromosome I of 2,117,144 bp and chromosome II of 1,177,787 bp. The number of open reading frames (ORFs) identified is 3,197, and 78\% were assigned functions. Of the proteins encoded by the remaining ORFs, two thirds are similar to proteins with a hypothetical function, and no homologies could be found for the remaining third. The origins of replication are similar to those of bacteria belonging to the $\alpha$ subgroup of the proteobacteria; the average $\mathrm{G}+\mathrm{C}$ content is $57 \%$ and no plasmids were found. Functionally, $67 \%$ of the ORFs have roles in transcription or translation and 20 ORFs are involved in signal transduction. B. melitensis does not secrete proteins that degrade carbohydrates, but it contains several ATP-binding cassette and other transport systems involved in carbohydrate import. This bacterium is able to synthesize and metabolize fatty acids, as well as lipid A, phospholipids and isoprenoids. Interestingly, B. melitensis is able to produce phosphatidylcholine, a phospholipid that is common in eukaryotes. It cannot fix atmospheric nitrogen, but several enzymes for oxidizing nitrogen 
compounds were identified. Although B. melitensis is nonmotile, it contains several flagellar operons. It does not seem to secrete proteins via the classical type-I, -II, or -III secretion systems, but does have 12 ORFs required to build a type-IV secretion system together with three that form a type-V secretion system, known as the flagellar-specific secretion system. Forty-one ORFs encode transposases and 30 possible insertion sequences were found, 22 on chromosome I and 8 on chromosome II. Eight of these insertion sequences were similar to insertion sequences in Mesorhizobium, belonging to the Rhizobiaceae, Gram-negative bacteria that can establish a symbiotic interaction with legume plants. Finally, genes involved in the production of virulence factors, including hemolysin, $\beta$-hemolysin, hemolysin III and invasins, were located. Interestingly, a homolog of the NodV/NodW two-component system, which regulates the expression of some of the nodulation genes in the plant symbiont Bradyrhizobium japonicum, was found in the genome of B. melitensis.

\section{Links}

Additional information about Integrated Genomics, the company that completed the sequencing, and the genome sequence of B. melitensis are available at the Integrated Genomics website.

\section{Conclusions}

From their study of the entire genome sequence, DelVecchio et al. come up with a set of interesting questions, the answers to which will contribute to the understanding of Brucella pathogenesis. Several secretion systems are present and the proteins secreted by these systems, as well as their role during infection, need to be studied. Although $B$. melitensis is nonmotile, several genes involved in the construction of flagella were noticed. Did this pathogen evolve from a motile bacterium to a nonmotile derivative that uses some of the flagellar proteins to form a needle that injects toxins into host cells?

\section{Reporter's comments}

This report of the entire genome sequence of B. melitensis will form the basis of further research required to understand how this pathogen infects and invades eukaryotic host cells and how it can survive and persist within them. As DelVecchio et al. note, microarray technology and proteomics will be the tools for such future studies, to get global insights on gene expression and protein synthesis under different environmental conditions, mimicking those present within the host cellular compartments. This should be a step towards developing a vaccine for use in humans. Future research may also be able to identify a set of proteins required for infection and/or survival in eukaryotic host cells that can be used to screen for drugs that inhibit these proteins' functions and which can therefore be used to treat infected people. 


\section{Table of links}

Proceedings of the National Academy of Sciences of the United States of America

Integrated Genomics website

\section{References}

1. DelVecchio VG, Kapatral V, Redkar RJ, Patra G, Mujer C, Los T, Ivanova N, Anderson I, Bhattacharyya A, Lykidis A, et al: The genome sequence of the facultative intracellular pathogen Brucella melitensis. Proc Natl Acad Sci USA. 2002, 98: 443-448. 0027-8424 